\title{
Nurse's knowledge and Practice regarding Medication Errors in Critical Care Units: Descriptive study
}

\author{
Al Shaimaa Moustafa Fathy1, Nahla Shaaban Khalil2, Naser Mohamed Taha3, Marwa M.Abd-elbaky4
}

(1) B. sc in critical care nursing, Faculty of Nursing, Minia University, Egypt.

(2) Assist Professor of Critical care Nursing Department, Cairo university

(3) Professor of Cardiology, Faculty of Medicine, Minia University, Egypt.

(4) Lecturer of Medical Surgical Nursing, (critical care nursing), Faculty of Nursing, MiniaUniversity, Egypt.

\begin{abstract}
:
Medication administration should be an error-free process as possible. Critical care nurse need to be diligent in discouraging interruptions to prevent harm to the patients who are being cared for. Medication administration errors are a constant occurrence on the unit, and patient safety must be a focus. Aim: to assess nurse's knowledge and practice regarding medication errors in critical care units. Design: Descriptive exploratory design was utilized to conduct the current study. Settings: The study was conducted in the following critical care units affiliated to Al minia University Hospital ; Intensive care, neurosurgical care, cardiac care, chest care and finally stroke unit. Sampling: A convenient sample consisted of 60 nurses was obtained from previously mentioned settings regardless of their personal characteristics. Tools: Two tools were used; First ; A structural interviewing questionnaire to collect demographic data of the studied nurses and their knowledge regarding medication administration errors. Second ; medication administration checklist to assess nurses' practice concerning medication administration errors. Results: The study findings showed that nurse's mean knowledge $($ Mean+SD $=\mathbf{1 0 . 7}+\mathbf{2 . 2 9})$ and practice $($ Mean+SD $=$ 23.1+4.58) scores were unsatisfactory regarding medication administration errors. Moreover, no significant differences were found among them by them regarding demographic characteristics' Conclusion: the mean nurse's knowledge and practice were low. Recommendations: The study recommended implementation of comprehensive, interactive, and continuous educational programs regarding drug administration errors
\end{abstract}

Keywords: Nurse's, knowledge, Practice, Medication \&Errors

\section{Introduction}

Many factors influence safe medication management. Some argue that registered nurses ( $\mathrm{RN})$ may have insufficient knowledge and skills to perform safe medication management others point to normalization of risk-inducing behavior and interruptions, or use of technology, design flaws, time constraints, and poor communication, lack of leadership, as well as outdated policies and guidelines. (Odberg et al., 2019). A study defined medication error (ME) as an error in prescribing, dispensing or administering of a drug, irrespective of whether such errors lead to adverse consequences or not (Dinkohs, 2016).

Each year, in the United States alone, 7000-9000 people die as a result of a ME. As specified by the Institute of Medicine (IOM), 400000 cases of preventable patient injury because of MEs occur each year in emergency clinics in the USA. It is observed that $19 \%$ of MEs in the ICU are lifethreatening and $42 \%$ are sufficient or clinically importance to warrant additional life-sustaining treatments. Besides, the total cost to manage patients with medication-associated errors exceeds $\$ 40$ billion each year. In agreement with that, MEs extend hospital stays by 2 days and increase the costs by \$2000-\$2500 per each patient. (Alrabadi et al., 2020)

Errors can occur at different stages of the medication use process. Medication errors occur when weak medication systems and/or human factors such as fatigue, poor environmental conditions or staff shortages affect prescribing, transcribing, dispensing, administration and monitoring practices, which can then result in severe harm, disability and even death. (Abdelhamed, 2020)

The incidence of medication errors in sectors such as emergency rooms and Intensive Care Units (ICUs) is higher due to a large number of patients. In particular, patients who admitted to ICUs receive medications mostly through their

$P$ a g e | 111 veins that often requires calculation of infusion drop rate. On the other hand, these patients are mostly in poor condition or unconscious and unable to monitor and report adverse drug reactions. Therefore, there may be more medication errors in such sectors that can have serious consequences. (Kaboodmehri et al., 2019)

Medication errors lead to an increase in the duration of hospitalization and disability and death in up to $6.5 \%$ of hospital admissions. (Abukhader \& Abukhader, 2020).Reducing errors and adverse events whilst maintaining patients' safety is dependent on a precise and timely evaluation of patients and interventions, which includes patient's risk assessment for developing inevitable and noninevitable complications. The process of assessment and evaluation of patients' safety risk is often challenging because of the vulnerable nature of acutely or critically ill patients combined with the stressful critical care environment (Shalaby et al., 2018).

\section{Significance of the study}

The World Health Organization (WHO) has emphasized that one in every ten patients is injured because of errors or adverse events during their hospital process in developed countries, that this rate is even higher in developing countries (World Health Organization. 2014)Error prevalence rates reported in a United Kingdom study found that $12 \%$ of all primary care patients may be affected by a prescribing or monitoring error over the course of a year, increasing to $38 \%$ in those 75 years and older and $30 \%$ in patients receiving five or more drugs during a 12-month period. Critical ill patient need special care and have increased incidence for medication error especially when caring with poor experienced nurse.

Al Shaimaa M., et al 


\section{Aim of the study}

The present study aimed to assess nurses' knowledge and practice regarding medication errors in selected critical care units at Minia University Hospital.

To achieve the aim of the study, the following research questions were formulated:

Research Questions:

(1) What is the nurses' knowledge level about medication errors in Critical Care Unitss?

(2) What is nurses' practice level regarding drug medication administration error in Critical Care Unitss?

(3) What is the relationship between nurses' knowledge and practice regarding drug medication administration errors in Critical CareUnits?

\section{Subjects and Methods \\ Subjects}

All nurses on duty and work in critical care units and administer medication to their patients were included in the current study regardless of their demographic characteristics

\author{
Research design \\ Descriptive exploratory research design was utilized \\ in the study.
}

\section{Setting}

The current study was carried out at five critical care units affiliated to Minia University Hospitals (traumatic intensive care unit, neurosurgical intensive care unit, cardiology care unit, chest intensive care unit, stroke unit).

\section{Tools for data collection}

Two tools were designed and used for data collection. These tools were formulated by the researchers after extensive literature review.

Tool 1: knowledge assessment structured questionnaire: It included two parts:

Part one: it included nurses' demographic such as sex, age, educational level, work area and years of experience.

Part two: medication errors knowledge
questionnaire

This questionnaire was utilized to assess nurses' knowledge regarding medication the questionnaire. it included 21 items that covered three categories of knowledge as follows ; general medication administration errors (7 items), medication preparation (3 items), and medication administration (11 items) .

\section{Scoring system of knowledge questionnaire}

Each correct answer was scored one grade and each false answer was scored zero score. Finally the scores were calculated summed up. The total scores ranged from 0 to 21 . The Satisfactory knowledge level was considered to be $\geq 75 \%$. And unsatisfactory knowledge level $<75$.

\section{Tool (2): Observational checklist of medication errors:}

The observational checklist was developed by the researchers based on thorough literature review and used to evaluate nurses' practices in medication administration. The entire checklist included 35 action steps. The checklist included three main categories; nursing performance during medication preparation (20 items), nursing practices during medication administration (10 items), nursing practices after medication administration (5 items).

\section{Scoring system of observational checklist of drug administration}

Each complete and correct done step obtained one score, and" not done" or incorrect action step obtained take zero score. The Satisfactory practice level was $\geq 80 \%$ and more. And unsatisfactory practice level was $<80 \%$

\section{Tools validity and Reliability:}

Content validity was done to identify the degree to which the used tools measure what was supposed to be measured. The developed tools were examined by a panel of five experts in the field of medical surgical nursing department and medical staff related to critically ill specialty in \{Minia University and Cairo University - Faculty of Nursing. All jury members agreed that current study tools were valid and relevant to the aim of the study. Reliability was done to identify the extent to which the tools items were measurable with the study concept and its correlation with each other, and the interclass correlation coefficient revealed $\mathrm{r}=0.9$.

\section{Pilot study:}

A pilot study was carried out on $10 \%$ of the study sample to test feasibility, objectivity, and applicability of the data collection tools. Carrying out the pilot study gave the investigator the experience to deal with the included subjects and to be familiar with the data collection tools. Based on the results of the pilot study, no modification or refinement was done and the subjects were included in the actual sample.

\section{Ethical considerations:}

An official permission to conduct the study was obtained from the ethical committee in the faculty of nursing at Al Minia University. As well, written consents and permission were also obtained managers of critical care units affiliated to al Minia university hospitals. Moreover, nurses who participated in this study were provided information concerning the purpose, benefits, and nature of the study. Each nurse had the right to withdraw from the study at any time without any rational. Confidentiality and anonymity of each subject were ensured through coding of all data and protecting the obtained data.

\section{Procedure:}

The researchers initiated data collection through contact with the studied nurses to explain the aim and nature of the study. Structured knowledge questionnaire were received by nurses in selected critical care units. The time allowed for nurses to complete the knowledge questionnaire was 45 minutes later, according to the schedule shift of nurses, the researchers put their plan to observe the nurses during administration of medications to their patients in morning and afternoon shifts utilizing observational checklists. The data collection lasted for seven months starting from September 2019 to March 2020. 
Minia Scientific Nursing Journal (Print - ISSN 2537-012X) (Online - ISSN 2785-9797) Vol. (8) No. (1) December 2020

\section{Statistical design}

The collected data was reviewed, organized, categorized and tabulated. Later, data entry and analysis was carried out through SPSS20 statistical software package .Quantitative data was presented in the form of mean, standard deviation. As well, T- test was used for comparison between two means. Qualitative data was presented in the form of numbers and percentage. It was analyzed in the form of chi square, fisher exact test. $\leq 0.05$ was adopted to be the level of significance in the current study.

Results

Table (1) Distribution of nurses demographic data $(n=60)$

\begin{tabular}{|c|c|c|}
\hline Characteristics & $\mathbf{N}$ & $\%$ \\
\hline \multicolumn{3}{|l|}{ Age } \\
\hline 20-29 year & 48 & 80 \\
\hline $30-39$ year & 6 & 10 \\
\hline$>40$ year & 6 & 10 \\
\hline \multicolumn{3}{|c|}{ Mean + SD $=26.7+1.30$} \\
\hline \multicolumn{3}{|c|}{ Years of experience } \\
\hline $1-3 \mathrm{yrs}$ & 31 & 51.7 \\
\hline $4-6 \mathrm{yrs}$ & 18 & 30 \\
\hline $7-10 \mathrm{yrs}$ & 9 & 15 \\
\hline$<10 \mathrm{yrs}$ & 2 & 3.3 \\
\hline \multicolumn{3}{|l|}{ Qualification } \\
\hline Diploma & 13 & 21.7 \\
\hline Technical & 37 & 61.6 \\
\hline Bachelor & 10 & 16.7 \\
\hline \multicolumn{3}{|l|}{ Time } \\
\hline Morning & 33 & 55 \\
\hline Evening & 17 & 28.3 \\
\hline Night & 10 & 16.7 \\
\hline
\end{tabular}

Table (1) Revealed that most of nurses, their age ranged between( $20-29)$ years with the mean age $(26.7+1.30)$ years. regarding nurses level of education, nearly two thirds of nurses $(61.6 \%)$ were technical institute graduation . concerning years of experience ,their years of experience ranged from( 1-3) years. finally, regarding the time of shift the nurses works, it revealed that more than half of nurses working in morning shifts $(55 \%)$.

Table (2) Frequency distribution of critical care nurses knowledge level regarding medication administration errors in CCUs $(\mathbf{N}=60)$

\begin{tabular}{|c|c|c|c|c|c|}
\hline \multirow{3}{*}{ NO } & \multirow[t]{3}{*}{ Variable } & \multicolumn{4}{|c|}{ Staff nurses knowledge level } \\
\hline & & \multicolumn{2}{|c|}{ Unsatisfactory } & \multicolumn{2}{|c|}{ Satisfactory } \\
\hline & & $\mathbf{N}$ & $\%$ & $\mathbf{N}$ & $\%$ \\
\hline \multirow{2}{*}{1.} & General knowledge of mediations administration errors & 48 & 80 & 12 & 20 \\
\hline & \multicolumn{5}{|l|}{ Mean+SD =3.67+1.31 } \\
\hline \multirow{2}{*}{2.} & Medication preparation errors & 25 & 41.7 & 35 & 58.3 \\
\hline & \multicolumn{5}{|l|}{ Mean+SD $=1.58+0.67$} \\
\hline \multirow{2}{*}{3.} & Medication administration errors & 55 & 91.7 & 5 & 8.3 \\
\hline & \multicolumn{5}{|l|}{ Mean + SD $=5.48+1.44$} \\
\hline \multirow{2}{*}{4} & Total knowledge & 59 & 98.3 & 1 & 1.7 \\
\hline & \multicolumn{5}{|l|}{ Mean+SD =10.7+2.29 } \\
\hline
\end{tabular}

Table (2): It is apparent that most of nurses obtained unsatisfactory knowledge level $(91.7 \% \& 80 \%)$ with $($ Mean $=5.48+1.44$ $\&(3.67+1.31))$ regarding general knowledge \&medication administration errors respectively .On the other hand, $(58.3 \%)$ only had got satisfactory level regarding Medication preparation errors with Mean (1.58 \pm 0.67$)$.

\section{Table (3): Critical care nurses mean practice score regarding medication sub items $(\mathrm{N}=60)$}

\begin{tabular}{|c|c|c|c|c|}
\hline \multirow[t]{2}{*}{ Performance dimensions } & \multicolumn{4}{|c|}{ Staff nurses performance } \\
\hline & Mean +SD & Min & Max & Range \\
\hline Preparation of medication & $13.65+2.97$ & 9 & 20 & 11 \\
\hline During medication administration & $6.07+1.61$ & 3 & 10 & 7 \\
\hline After medication administration & $3.37+0.84$ & 1 & 5 & 4 \\
\hline Total practice & $.23 .1+4.58$ & 14 & 32 & 18 \\
\hline
\end{tabular}

Table (3): As can be seen that the overall mean practice score was $(23.1+4.58)$ out of( 32$)$.so, they gained (13.65+2.97) out of (20) in Preparation of medication. While they got low mean score ( 3.37+0.84) out of (5)after medication administration. 


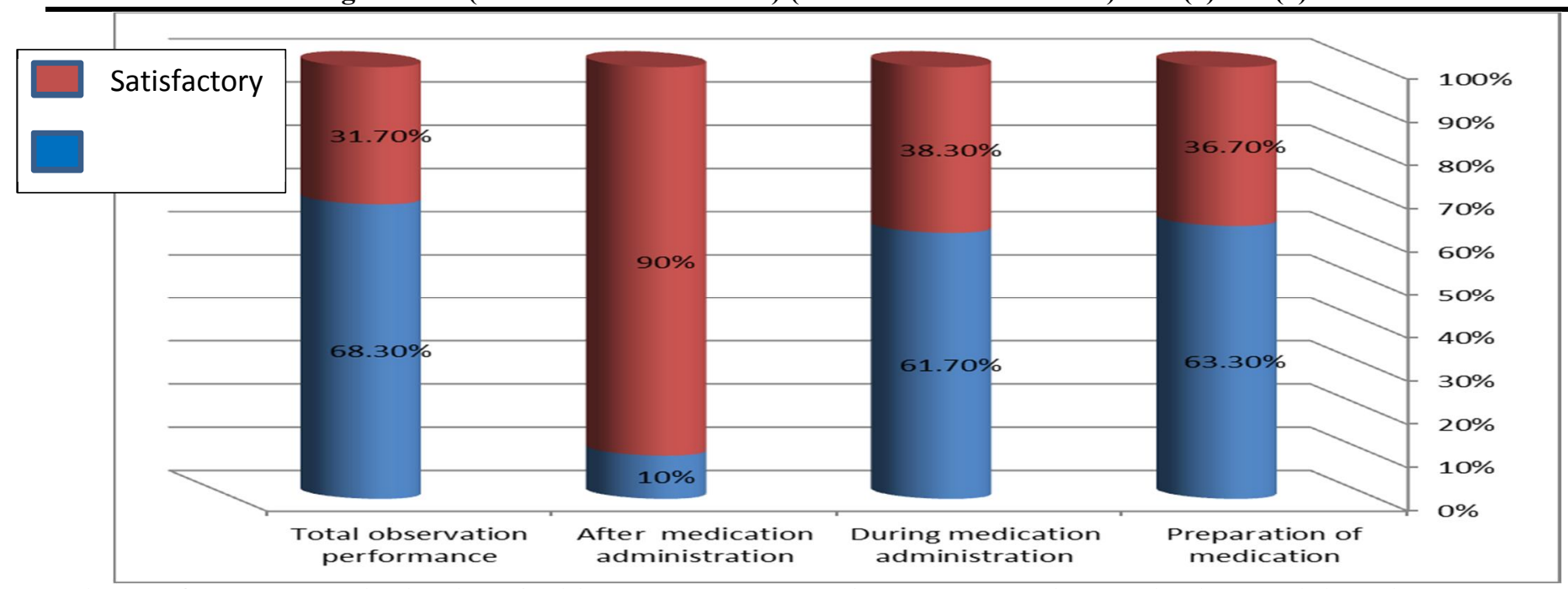

Figure (4) Frequency distribution of critical care nurses practices level regarding medication administration errors $(\mathrm{N}=60)$

Figure (4) Illustrated that almost two thirds (63.30\%) had unsatisfactory practices in Preparation of medication. While (90\%) had satisfactory practices after medication administration

Table (4) Correlation of nurses total knowledge with practices sub items regards medication administration(n=60).

\begin{tabular}{|c|c|c|c|c|c|c|c|}
\hline Variable & & 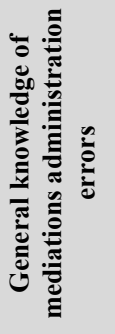 & 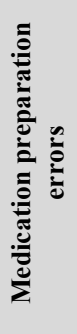 & 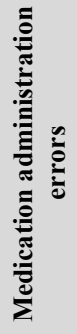 & 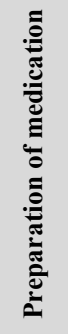 & 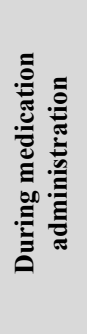 & 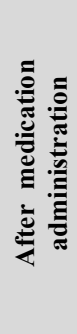 \\
\hline total knowledge of mediations administration errors & $\begin{array}{l}\mathbf{r} \\
\mathbf{p}\end{array}$ & 1 & $\begin{array}{c}.045- \\
.733 \\
\end{array}$ & $\begin{array}{l}.248 \\
.056 \\
\end{array}$ & $\begin{array}{l}.130 \\
.320 \\
\end{array}$ & $\begin{array}{c}-.174- \\
.185 \\
\end{array}$ & $\begin{array}{l}.251 \\
.053 \\
\end{array}$ \\
\hline Medication preparation errors & $\begin{array}{l}\mathbf{r} \\
\mathbf{p}\end{array}$ & - & 1 & $\begin{array}{l}.089 \\
.499 \\
\end{array}$ & $\begin{array}{l}.197 \\
.131 \\
\end{array}$ & $\begin{array}{l}.292^{*} \\
.024 \\
\end{array}$ & $\begin{array}{l}.305^{*} \\
.018\end{array}$ \\
\hline Medication administration errors & $\begin{array}{l}\mathbf{r} \\
\mathbf{p}\end{array}$ & - & - & 1 & $\begin{array}{l}.080 \\
.546\end{array}$ & $\begin{array}{l}.037 \\
.780 \\
\end{array}$ & $\begin{array}{c}-.148- \\
.259 \\
\end{array}$ \\
\hline Preparation of medication & $\begin{array}{l}\mathbf{r} \\
\mathbf{p}\end{array}$ & & & & 1 & $\begin{array}{c}.549^{* *} \\
.000 \\
\end{array}$ & $\begin{array}{c}.458^{* * *} \\
.000\end{array}$ \\
\hline During medication administration & $\begin{array}{l}\mathbf{r} \\
\mathbf{p}\end{array}$ & & & & & 1 & $\begin{array}{c}.467^{* * *} \\
.000\end{array}$ \\
\hline After medication administration & $\begin{array}{l}\mathbf{r} \\
\mathbf{p}\end{array}$ & & & & & & 1 \\
\hline
\end{tabular}

Table (4) Showed that there were a fair positive correl ation between critical care nurse practice after medication administration with their knowledge about medication preparation errors, their practices in medication preparation, and during medication administration. $(\mathrm{r}=.305, \mathrm{P}-$ Value $<.018, \mathrm{r}=.458, \mathrm{P}-$ Value $<.0001, \mathrm{r}=.467, \mathrm{P}-$ Value $<.0001$ respectively). Likewise, there was reasonable positive relationship between critical care nurse practice during medication administration with their medication preparation $(\mathrm{r}=.549, \mathrm{P}$ value $<.001)$.

Table (5) Correlation of nurses total knowledge with practices sub items $(n=60)$.

\begin{tabular}{|c|c|c|c|c|c|c|}
\hline Variable & & $\begin{array}{c}\text { Preparation } \\
\text { of } \\
\text { medication }\end{array}$ & $\begin{array}{c}\text { During } \\
\text { medication } \\
\text { administration }\end{array}$ & $\begin{array}{c}\text { After } \\
\text { medication } \\
\text { administration }\end{array}$ & Total practice & $\begin{array}{c}\text { Total } \\
\text { knowledge }\end{array}$ \\
\hline Preparation of medication & $\begin{array}{l}\mathbf{R} \\
\mathbf{P}\end{array}$ & 1 & $\begin{array}{l}.549^{* *} \\
.000\end{array}$ & $\begin{array}{l}.458^{* *} \\
.000\end{array}$ & $\begin{array}{l}.927^{* *} \\
.000\end{array}$ & $\begin{array}{l}.182 \\
.164 \\
\end{array}$ \\
\hline During medication administration & $\begin{array}{l}\mathbf{R} \\
\mathbf{P}\end{array}$ & - & 1 & $\begin{array}{l}.467^{* *} \\
.000 \\
\end{array}$ & $\begin{array}{l}.794^{* *} \\
.000\end{array}$ & $\begin{array}{l}.009 \\
.943 \\
\end{array}$ \\
\hline After medication administration & $\begin{array}{l}\mathbf{R} \\
\mathbf{P}\end{array}$ & - & - & 1 & $\begin{array}{l}.646^{* *} \\
.000\end{array}$ & $\begin{array}{l}.139 \\
.290 \\
\end{array}$ \\
\hline Total practice & $\begin{array}{l}\mathbf{R} \\
\mathbf{P}\end{array}$ & - & - & - & 1 & $\begin{array}{l}.147 \\
.262\end{array}$ \\
\hline
\end{tabular}

Table (5) Positive correlation between total practice of critical care nurse and their performance in preparation of medication and during medication administration $(\mathrm{r}=.927, \mathrm{P}-$ value $<.0001 \& \mathrm{r}=.794, \mathrm{P}-$ value $<.0001$ respectively), fair positive relationship between critical care nurse performance during medication administration with their preparation of medication and total 
observation performance of critical care nurse with their performance after medication administration $(\mathrm{r}=.549, \mathrm{P}-$ value $<.0001 \& \mathrm{r}$ $=.646, \mathrm{P}-$ value $<.0001$ respectively), and moderate positive correlation between critical care nurse performance after drug administration with their drug preparation and during drug administration $(\mathrm{r}=.458, \mathrm{P}-$ value $<.0001 \& \mathrm{r}=.467, \mathrm{P}-$ value $<.0001$ respectively).

Table ( 6 ): Frequency distribution of critical care nurses MCQ responses regards general knowledge of medications administration and preparation errors $(\mathrm{No}=60)$

\begin{tabular}{|c|c|c|c|c|}
\hline \multirow{3}{*}{ Items } & \multicolumn{4}{|c|}{ General knowledge of mediations administration } \\
\hline & \multicolumn{2}{|c|}{ False } & \multicolumn{2}{|c|}{ True } \\
\hline & $\mathbf{N}$ & $\%$ & $\mathbf{N}$ & $\%$ \\
\hline 1- Definition of Medication administration Error. & 37 & 61.7 & 23 & 38.3 \\
\hline 2-Hazards of medication error? & 16 & 26.7 & 44 & 73.3 \\
\hline 3- Prevention of medication errors? & 16 & 26.7 & 44 & 73.3 \\
\hline 4-Nursing roles in the medication administration process & 32 & 53.3 & 28 & 46.7 \\
\hline 5-patient "rights" should be checked by nurse before medication administration? & 54 & 90 & 6 & 10 \\
\hline 6-Examples of medication errors? & 36 & 60 & 24 & 40 \\
\hline \multirow[t]{2}{*}{ 7- Examples of medication error report be filled out and submitted? } & 9 & 15 & 51 & 85 \\
\hline & \multicolumn{4}{|c|}{ Medication preparation related errors } \\
\hline 8-To make sure you have the right medication, & 20 & 33.3 & 40 & 66.7 \\
\hline 9-To make sure you have the "right individual. & 44 & 73.3 & 16 & 26.7 \\
\hline $\begin{array}{l}\text { 10-When the medication is received; you must read the } \\
\text { and copy the information to the patient's }\end{array}$ & 21 & 35 & 39 & 65 \\
\hline
\end{tabular}

Table ( 6 ): Shows that that most of nurses (90\%) obtained false answer in question no (5) pertained to patients' rights. As well, ( (73.3\%, 61.7\%,60\%and53.3\% )obtained false answers pertained to right individual ,definition ,examples of medication errors and role of nurse in medication administration. On the other hand, nearly three fourth (73.3) gained correct answer in question no (2\&3) pertained to hazards and prevention of medication errors. While $(66.7 \%, 65 \%$ respectively) had true answer regarding question no $(8-10)$ related to right medication and documentation of medication.

Table (7): Frequency distribution of critical care nurses MCQ responses regards medication administration errors $($ No $=60)$

\begin{tabular}{|c|c|c|c|c|}
\hline \multirow{3}{*}{ Items } & \multicolumn{4}{|c|}{ Medication Administration related errors } \\
\hline & \multicolumn{2}{|c|}{ False } & \multicolumn{2}{|c|}{ True } \\
\hline & $\mathbf{N}$ & $\%$ & $\mathbf{N}$ & $\%$ \\
\hline 11Time for documentation of medications administration: & 53 & 88.3 & 7 & 11.7 \\
\hline 12-For "right dose" you must check & 15 & 25 & 45 & 75 \\
\hline 13-If you pour more liquid medication into the measuring cup than is needed, you: & 28 & 46.7 & 32 & 53.3 \\
\hline $\begin{array}{l}\text { 14-During medication administration, you find a medication container that is not listed on the Medication } \\
\text { Administration Record (MAR). What should you do? }\end{array}$ & 22 & 36.7 & 38 & 63.3 \\
\hline $\begin{array}{l}\text { 15-If you have a medication listed on the Medication Administration Record (MAR) but it is not in the } \\
\text { medication cart/drawer/bubble pack, what should you do? }\end{array}$ & 33 & 55 & 27 & 45 \\
\hline 16- Position the client should be when you are inserting a suppository? & 15 & 25 & 45 & 75 \\
\hline 17- Examples of medication need monitoring of vital signs? & 39 & 65 & 21 & 35 \\
\hline 18- Examples of medication should be administered slowly? & 40 & 66.7 & 20 & 33.3 \\
\hline 19- The minimum amount of time a patient must be observed after taking IV medication for the first time? & 58 & 96.7 & 2 & 3.3 \\
\hline 20- Recommended route for heparin injections is & 15 & 25 & 45 & 75 \\
\hline 21-Advising about medication knowledge is recommended for: & 13 & 21.7 & 47 & 78.3 \\
\hline
\end{tabular}

Table (7): As can be seen that most of nurses (96.7\% and $88.3 \%$ respectively) had got false answer in question no( $11 \& 19)$ related to time of documentation and minimum amount of time a patient must be observed after taking IV medication. On the other hand, three fourth of nurses $(75 \%)$ had got true answer related to question no $(16,20)$ related to recommended route for heparin injections and right position for inserting a suppository.

Table (8): Frequency distribution of critical care nurses (done $\backslash$ not done) practices during preparation of medication $(\mathrm{No}=60)$

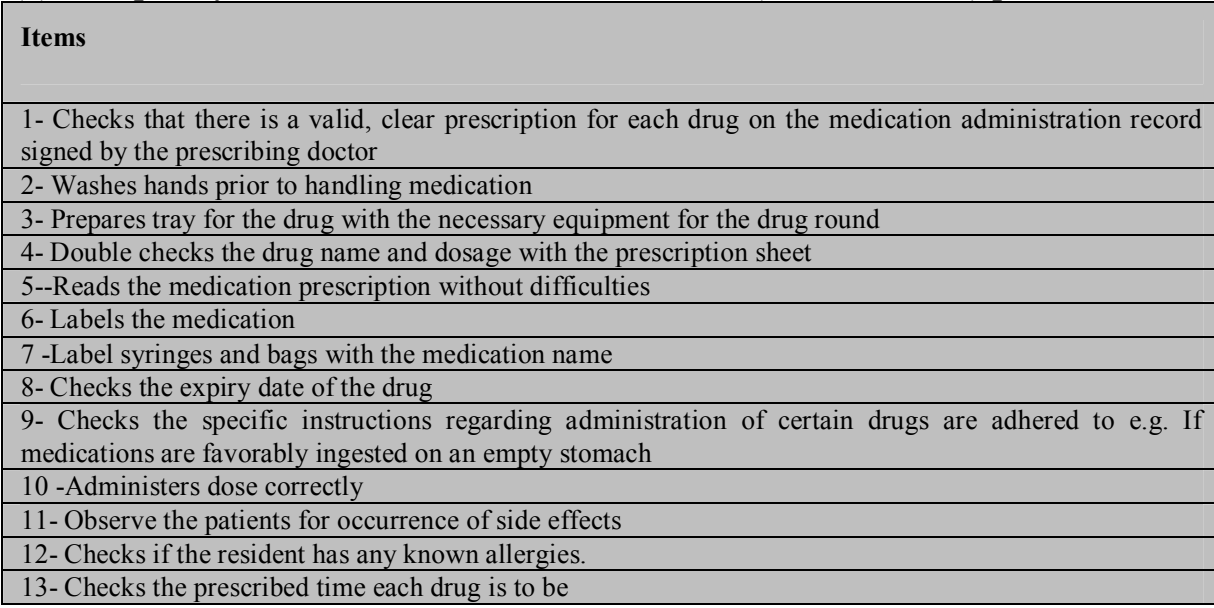

\begin{tabular}{|l|l|l|l|}
\hline \multicolumn{4}{|l|}{ Medication preparation } \\
\hline \multicolumn{3}{|l|}{ Not done } & \multicolumn{1}{l|}{ Done } \\
\hline N & $\%$ & N & $\%$ \\
\hline 1 & 1.7 & 59 & 98.3 \\
\hline 27 & 45 & 33 & 55 \\
\hline 26 & 43.3 & 34 & 56.7 \\
\hline 38 & 63.3 & 22 & 36.7 \\
\hline 2 & 3.3 & 58 & 96.7 \\
\hline 15 & 25 & 45 & 75 \\
\hline 27 & 45 & 33 & 55 \\
\hline 15 & 25 & 45 & 75 \\
\hline 41 & 68.3 & 19 & 31.7 \\
\hline 8 & 13.3 & 52 & 86.7 \\
\hline 28 & 46.7 & 32 & 53.3 \\
\hline 30 & 50 & 30 & 50 \\
\hline 7 & 11.7 & 53 & 88.3 \\
\hline
\end{tabular}




\begin{tabular}{|c|c|c|c|c|}
\hline \multirow{3}{*}{ Items } & \multicolumn{4}{|c|}{ Medication preparation } \\
\hline & \multicolumn{2}{|c|}{ Not done } & \multicolumn{2}{|c|}{ Done } \\
\hline & $\mathrm{N}$ & $\%$ & $\mathbf{N}$ & $\%$ \\
\hline 14- Checks when the drug was last administered & 6 & 10 & 54 & 90 \\
\hline 15- Check that medication is administered at the right time that is not $\geq 60 \mathrm{~min}$ earlier or late & 3 & 5 & 57 & 95 \\
\hline 16- Checks the prescribed dose of each drug in the chart & 6 & 10 & 54 & 90 \\
\hline 17- Checks the prescribed route and form of each drug & 0 & 0 & 60 & 100 \\
\hline 18- Uses medicine pots, cups or spoons to avoid making contact with the drug. & 31 & 51.7 & 29 & 48.3 \\
\hline $\begin{array}{l}\text { 19- Crushed medicines, the nurse establishes that these have been sanctioned by a medical practitioner or } \\
\text { pharmacist. A clean pestle and mortar is used and it is cleaned after each resident with warm water and } \\
\text { detergent and wiped with a dry hand towel. }\end{array}$ & 47 & 78.3 & 13 & 21.7 \\
\hline 20- Checked drugs for the same name and strength if in a monitored dosage system. & 23 & 38.3 & 37 & 61.7 \\
\hline
\end{tabular}

Table (8): It is apparent that nearly two thirds and three fourth of nurses $(68.3 \% \& 78.3 \%$ respectively) didn't Checks instructions regarding administration of drugs, Crushed medicines, the nurse establishes that these have been sanctioned by a medical practitioner or pharmacist. A clean pestle and mortar is used and it is cleaned after each resident with warm water and detergent and wiped with a dry hand towel.. On the other hand, most of nurses $(100 \%, 98.3 \%, 96.7 \%, 90 \%, 88.3 \%, 86.7 \%)$ checked the prescribed route and form of each drug, checked that there is a valid, clear prescription for each drug, reads the medication prescription without difficulties, checks the prescribed dose, checked the prescribed time and finally administered dose correctly.

Table (9): Frequency distribution of critical care nurses donelnot done practices during and after administration of drug (No $=60)$

\begin{tabular}{|c|c|c|c|c|}
\hline \multirow[t]{3}{*}{ Items } & \multicolumn{4}{|c|}{ During administration of drug } \\
\hline & \multicolumn{2}{|c|}{ Not Done } & \multicolumn{2}{|c|}{ Done } \\
\hline & $\mathbf{N}$ & $\%$ & $\mathbf{N}$ & $\%$ \\
\hline 21- Verifies the patient's identity prior to administering medication & 1 & 1.7 & 59 & 98.3 \\
\hline $\begin{array}{l}\text { 22- Communicates information sensitively to the resident prior to and during administration } \\
\text { of medication }\end{array}$ & 36 & 60 & 24 & 40 \\
\hline $\begin{array}{l}\text { 23-Administered all medicines are personally by the dispensing nurse immediately following } \\
\text { preparation }\end{array}$ & 13 & 21.7 & 47 & 78.3 \\
\hline 24- Stays with the resident until the drug has been swallowed. & 19 & 31.7 & 41 & 68.3 \\
\hline 25- Not to leave medicines for the resident to se lf-administer at a later time. & 0 & 0 & 60 & 100 \\
\hline 26- Documents any delay or omission in the nursing notes/ & 46 & 76.7 & 14 & 23.3 \\
\hline $\begin{array}{l}\text { 27- Dispose non administered and wasted drugs or sharps in the appropriate designated } \\
\text { sealed container. }\end{array}$ & 15 & 25 & 45 & 75 \\
\hline $\begin{array}{l}\text { 28- Signs their usual abbreviations on the medication administration record / prescription } \\
\text { sheet as soon as the medication has been administered }\end{array}$ & 36 & 60 & 24 & 40 \\
\hline 29-Stay with patient for several minutes, and observe for any allergic reaction & 30 & 50 & 30 & 50 \\
\hline \multirow[t]{2}{*}{ 30- Cleans their hands between residents } & 40 & 66.7 & 20 & 33.3 \\
\hline & \multicolumn{4}{|c|}{ After administration of drug } \\
\hline 31- Monitors the tasks to the administered medication & 12 & 20 & 48 & 80 \\
\hline 32- Records monitoring data related to administered medication & 35 & 58.3 & 25 & 41.7 \\
\hline 33- Reports the abnormal findings to physician & 0 & 0 & 60 & 100 \\
\hline 34-Demonstrate knowledge related to administered medication with patient. & 24 & 40 & 36 & 60 \\
\hline 35- Make sure that information is soundly understood by patients & 27 & 45 & 33 & 55 \\
\hline
\end{tabular}

Table (9): Showed that two thirds $(60 \%)$ of nurses didn't Communicates information sensitively to the resident prior to and during administration of medication step no (22),(58.3\%) of nurses didn't Records monitoring data related to administered medication. On the other hand, most of nurses $(98.3 \%)$ Verifies the patient's identity prior to administering medication step no (21). As well, $(78.3 \% \& 75 \%)$ three fourth of nurses Administered all medicines are personally by the dispensing nurse immediately following preparation and Dispose non administered and wasted drugs or sharps in the appropriate designated sealed container step no $(23,27)$. While all nurses $(100 \%)$ Reports the abnormal findings to physician.

\section{Discussion}

Regarding the demographic characteristics of the study subjects, the current study revealed that, the most of the critical care nurses aged was between (20-29) years and their mean average \pm SD was $(26.7 \pm 1.30)$ years: This may be due to the desire of university's hospital to provide high-quality health care services, through employing new graduates of the faculty of nursing or nursing technical institute in critical units.

As regards their qualification result found that more than half of them $(61.6 \%)$ had graduated from technical institute degree in nursing. This may be explained by a little number of faculty's graduates had employed in the university hospital and other work in schools or ministry of health hospital. On the other hand, the highest percentage of them constituted (96.7\%) had from (1-3) years of experience working at critical units.. Finally, more than half of the study

P a g e | 116 group $(55 \%)$ works in morning shift. This may due to routine and increase work load at this time.

This result come in the line with (Sa'ed et al., 2019) who conducted a cross-sectional study named "Knowledge about the administration and regulation of high alert medications among nurses in Palestine" and reported that most of them were between the ages of 25-30 years, But the current study contrasts with the same author who reported that most of nurses had 5-10 years of total experience. And the majority of nurses had a bachelor degree in nursing.

Moreover, the current study contraindicated with (Alhashemi, Ghorbani, \& Vazin, 2019) who contemplated a case-control study entitled "Improving knowledge, attitudes, and practice of nurses in medication administration through enteral feeding tubes by clinical pharmacists" and detailed that the mean age of nurses was 32 years, and almost two third of them were ladies. By far most of participants in two groups 
had a four-year college education in nursing. Further, But the current study come in the line with the same author who reported that the mean years of experience among participants in a critical care unit and as a nurse was two and five years.

In addition this outcome comes in concur with (Farag, Eweda, \& Elsayed, 2017) who conducted a study titled "Nurses Knowledge and Practice in Dealing with High Alert Medications" and reported that short of what one third of the contemplated nurses were from (41 to less than 50) years old, while; of them, one fifth were $<30$ years old and the experience years of the most were $<18$ years in the relegated departments.

\section{Regarding Frequency distribution of critical care nurse's knowledge level regarding medication} administration errors in CCUs, the present study revealed that most of nurses obtained unsatisfactory knowledge regarding general knowledge \& MAEs respectively. This may due to inadequate training in the area, the absence of regular group discussion to refresh their knowledge regarding medication errors, lack of motivation, increased nursing workload which made the delay of nurses abilities and motives to acquire and update their knowledge. On the other hand more $(58.3 \%)$ only had got satisfactory level regarding medication preparation errors.

This result comes in the line with (Mansour, 2019) who studied "Effect of Maternity Nurses Knowledge and Practices Regarding the Medication Errors on Laboring Women Safety in Labor Unit" and reported that greater than half of the studied sample had incomplete satisfactory information.

But his result differs with (Samundeeswari \& Muthamilselvi, 2018) who studied "Nurses Knowledge on Prevention of Medication Error" and reported that one third of the studied nurses are on average in the information of ME. Short of what one third of nurses have poor information, slightly above quarter of nurses have very low level of knowledge and only $8 \%$ of nurses had good information on prevention of ME.

Additionally, the current study contraindicated with (Dyab, Elkalmi, Bux, \& Jamshed, 2018) who studied “Exploration of Nurses' Knowledge, Attitudes, and Perceived Barriers towards Medication Error Reporting in a Tertiary Health Care Facility: A Qualitative Approach" and reported that the nurses were knowledgeable about Medication Error Reporting, however there was vulnerability towards detailing innocuous MEs. In addition, (Kaur \& Charan, 2018) who conducted "a study to assess the knowledge regarding medication error among staff nurses at SGRD hospital, Amritsar, Punja" reported that almost two third of nurses were on average knowledge followed by less than one third of them having poor score level.

Regarding critical care nurses mean practice score for medication's preparation, administration, and after administration .the current study revealed the overall mean practice score of critical care nurse was $23.1+4.58$ out of 32. Along these lines, they picked up $13.65+2.97$ out of 20 in preparation of drug. While they had low mean score $3.37+0.84$ out of 5 in After medication administration. This may due to lack of continuous educational programs and practice sessions regarding medication administration.

This result come in accordance with (Abd Elmageed et al, 2020) who delineated that the mean and standard deviation of the nurse's preparation for medication is $50.66 \pm 11.85$, while in drug administration it was $122.19 \pm 14.65$ and in nurses' practices post drug administration, it was $44.17 \pm 14.76$. In relation to the nurse's total practice for drug administration it scored 267.05 \pm 29.62 .

Besides, (Wabe, Raju, \& Angamo, 2011) who studied "Knowledge, attitude and practice of patient medication counseling among drug dispensers in North West Ethiopia" reported that post medicine practice requires improvement. This finding might be ascribed to the remaining workload that makes the nurses practice described by lowlevel of performance.

Concerning frequency distribution of critical care nurses practices level regarding medication administration errors, the present result showed that only more than onethird of them had satisfactory practices in the preparation of medication, only more than one third of them had satisfactory practices during medication administration, the majority of them had satisfactory level of practice after drug administration and only one third of them had total satisfactory performance about drug administration.

This result come in the line with who studied (Abd Elmageed et al, 2020) "Knowledge, Attitude and Practice of Nurses in Administering Medications at Mansoura University Hospitals" that greater than three quarters of the nurses have helpless practice score with respect to drug preparation, trailed by marginally greater than three fifths of them revealed poor practice level regarding medication administration as well. Besides, marginally under two fifths of the nurses have helpless practice post administering drug. Ultimately, around half of the nurses have poor total practice level.

Regarding the correlation matrix between nurses total knowledge with practices sub items regards medication administration, the present study showed that there were a fair positive correlation critical care nurse practice after medication administration with their knowledge about medication preparation errors, their practices in medication preparation, and during medication administration $(\mathrm{r}=.305, \mathrm{P}-$ Value $<.018, \mathrm{r}=.458, \mathrm{P}-$ Value $<.0001, \mathrm{r}=$ $.467, \mathrm{P}-$ Value $<.0001$ respectively). Likewise, there was reasonable positive relationship between critical care nurse practice during medication administration with their medication preparation $(\mathrm{r}=.549, \mathrm{P}$ value $<.001)$. This may due to lack of knowledge may have an effect on nurses practice. So they need for courses to update their knowledge and improving their practice

This come in accordance with (Bakr Abo El-Ata et al., 2019) who revealed that there were an exceptionally statistical significant correlation between knowledge and practices in MEs $(r=0.26$ and $p$ value $=0.02)$. this outcome was upheld by (Abd Elmageed et al, 2020) who reported that there is a measurably statistically significant relation between nurses' knowledge, practice and attitude in drug administration.

Regarding the Correlation matrix of nurses total knowledge, practices sub items the present study demonstrated that there were solid positive correlation between total observation performance of critical care nurse and their performance in preparation of medication and during medication administration $(\mathrm{r}=.927, \mathrm{P}-$ value $<.0001 \& \mathrm{r}=$ $.794, \mathrm{P}-$ value $<.0001$ respectively), fair positive relationship 
between critical care nurse performance during medication administration with their preparation of medication and total observation performance of critical care nurse with their performance after medication administration $(\mathrm{r}=.549, \mathrm{P}-$ value $<.0001 \& \mathrm{r}=.646, \mathrm{P}-$ value $<.0001$ respectively), and moderate positive correlation between critical care nurse performance after drug administration with their drug preparation and during drug administration $(\mathrm{r}=.458, \mathrm{P}-$ value $<.0001 \& \mathrm{r}=.467, \mathrm{P}-$ value $<.0001$ respectively).

This outcome comes as per (Márquez-Hernández et al., 2019) who studied "Factors related to medication errors in the preparation and administration of intravenous medication in the hospital environment" and revealed that there were measurably huge contrasts found between nurses knowledge and performance.

This result were confirmed by (Bakr Abo El-Ata et al., 2019) who revealed that there was a profoundly positive correlation between practice and knowledge of nurses and there was an indicative positive correlation between their attitude, knowledge and practice. Additionally (Hassan \& Ahmed, 2012) detailed a similar result.

Likewise (Shahin, Mohamed, \& Sayed, 2012) who studied "'Nurses' knowledge and practices regarding Enteral Nutrition at the critical care"' reported that a profoundly positive correlation between practice and knowledge of nurses. A similar result was outlined by (Abd Elmageed et al, 2020)

With respect to Critical care nurses MCQ responses regards general knowledge of medications administration and preparation errors, the current study showed that more than one third of nurses know the definition of MAEs, slightly less than three quarters of them identified the hazards of MEs and how to prevent them, less than half of them mentioned nursing roles in the MAEs, and only one tenth of them answered correctly patient's rights before medication administration. This result agrees with (Shaikh \& Al-Ruzaiqi, 2019) who conducted a study named "knowledge and perception of preventable medical errors in sultanate of Oman" and revealed that the most of participants had heard about the MEs and the majority of them were eager to know the MEs.

Furthermore this outcome was upheld by (Teal, 2019) who studied "Associate and baccalaureate degree nursing students' knowledge of and attitudes toward medication errors and reporting medication errors: implications for curriculum development" and revealed that at nursing students, they failed to define MEs, or to know its types, and causes. This study additionally found that students do not know how to report a ME.

But These results come inconsistent with (Di Muzio, De Vito, Tartaglini, \& Villari, 2017) who studied "Knowledge, behaviors, training and attitudes of nurses during preparation and administration of intravenous medications in intensive care units (ICU). A multicenter Italian study" and detailed that the most of the studied nurses were aware of MEs.

Regarding medication preparation errors the current study showed that less than two third of study group had false answer regarding they checked right patient in medication preparation errors while two third of them had true answer regarding they checked right medication, medication name and prescription of medication.
This outcome comes in accordance with (Bucknall et al., 2019) who studied 'Nurses' decision-making, practices and perceptions of patient involvement in medication administration in an acute hospital setting" and stated that most of the contemplated sample do checking for patient identification, the medication name, checking the dose, the route, and the time as well as patient education about medications, dose calculation, observing the patient while consuming the medications, checking medicine for another nurse in name, dose and route.

Yet, this finding contraindicated with (Abukhader \& Abukhader, 2020) who studied "Effect of Medication Safety Education Program on Intensive Care Nurses' Knowledge regarding Medication Errors" and detailed that the greater part of the contemplated test had agreeable information in regards to following the international patient safety goals and guidelines of intravenous drug administration.

Regarding critical care nurses MCQ responses regards medication administration errors, the present study showed that most of nurses had got false answer related to the time of documentation and the minimum amount of time a client must be observed after taking intravenous drug. On the other hand, three fourth of nurses had given true answers related to recommended route for heparin injections and position the client for suppository medication.

This come in accordance with (Bakr Abo El-Ata, Hassan Ibrahim, Saad Mohamed, \& Elsayed Ahmed Allawy, 2019) who studied 'Nurses' Performance Regarding Administration of Inotropic Medications for Critically Ill Patients" and revealed that the most of nurses had an unacceptable degree of knowledge and the majority of studied nurses had unsuitable complete practice with almost the majority of studied nurses had had an uplifting attitude toward administering inotropic drugs.

Likewise, this result come in the line with (Lan et al., 2014) who studied "Medication errors in pediatric nursing: Assessment of nurses' knowledge and analysis of the consequences of errors" and detailed that almost two third of the studied sample had unacceptable level of knowledge regarding drug administration.

The current result were confirmed by (Zarea, Mohammadi, Beiranvand, Hassani, \& Baraz, 2018) who studied "Iranian nurses' medication errors: A survey of the types, the causes, and the related factors" and reported that greater than half of the studied nurses giving medicine to patients later or earlier, greater than one third of them give multiple oral drugs together regardless of their interactions and greater than one third of them administering the postoperative pain relieving drugs without a prescription.

Regarding critical care nurses' done/not practices done during preparation of medication, the current study revealed that almost two thirds and three fourth of critical care nurses showed that they didn't check instructions regarding administration of drugs and crushed medicines, the nurse establishes that these have been sanctioned by a medical practitioner or pharmacist. A clean pestle and mortar is used and it is cleaned after each resident with warm water and detergent and wiped with a dry hand towel.. This might be identified with the absence of strategies and roles that controlling drug administration.

outcome comes conflicting with (Mahesh, Hajira Saba, \& Gopi, 2016) who studied "Nursing perceptions of 
medication administration practices, reasons for errors and reporting of errors in a tertiary care hospital, Bangalore" and reported that the majority of nurses consistently checked the composition of the medication before administration. This outcome is affirmed by (Westbrook, Rob, Woods, \& Parry, 2011) who detailed that most of the contemplated nurses didn't aware of drug protocol.

Likewise, the current study showed that the greater part of nurses checked the prescribed route and forms of each medication, checked that there is a valid, clear prescription for each drug, reads the medication prescription without difficulties, checked the prescribed dosage, checked the prescribed time and administered dose accurately.

This outcome comes as per (Mahesh et al., 2016) who detailed that most of the studied sample consistently checked the expiry date prior to administering the drug and consistently practice sterile technique for administering intramuscular and intravenous medications.

Likewise, this outcome was affirmed by (Karttunen, Sneck, Jokelainen, \& Elo, 2020) who studied 'Nurses' selfassessments of adherence to guidelines on safe medication preparation and administration in long-term elderly care" and revealed that nost members guaranteed to consistently get ready medicine as indicated by the relevant guidelines. (Gilani, 2020) Who studied "Practices of Nurses in Administration of Safe Medication" detailed a similar outcome.

This outcome comes as per (Bucknall et al., 2019) who studied 'Nurses' decision-making, practices and perceptions of patient involvement in medication administration in an acute hospital setting" and showed that most of the contemplated nurses checking patient identification, the drug name, the dosage, the route and the scheduled time prior to giving drug.

Regarding critical care nurses' done/not done practices during administration of drug, the current study showed that two thirds e nurses didn't communicate information sensitively to the resident before and during administration of medicine. This outcome come conflicting with (Bucknall et al., 2019) who expressed that the greater part of the contemplated nurses gives patient with required education about medicine.

On the other hand most of nurses confirmed the patient's identity before administering medication, three fourth of nurses administered all drugs are personally, and they disposed non administered and squandered drugs or sharps. this outcome comes as per (Karttunen et al., 2020) who

\section{Referenes}

(1) Abukhader, I., \& Abukhader, K. (2020). Effect of Medication Safety Education Program on Intensive Care Nurses' Knowledge regarding Medication Errors. Journal of Biosciences and Medicines, 8(6), 135-147

(2) Alhashemi, S. H., Ghorbani, R., \& Vazin, A. (2019). Improving knowledge, attitudes, and practice of nurses in medication administration through enteral feeding tubes by clinical pharmacists: a case-control study. Advances in Medical Education and Practice, 10, 493

(3) Bakr Abo El-Ata, A., Hassan Ibrahim, M., Saad Mohamed, A., \& Elsayed Ahmed Allawy, M. (2019). Nurses' Performance Regarding Administration of Inotropic Medications for Critically Ill Patients. Port Said Scientific Journal of Nursing, 6(1), 139-160 .

(4) Bucknall, T., Fossum, M., Hutchinson, A. M., Botti, M., Considine, J., Dunning, T., . . . Manias, E. (2019). Nurses' decision-making, practices and perceptions of patient involvement in medication administration in an acute hospital setting. Journal of advanced nursing, 75(6), 1316-1327 stated that over half the participants claimed to administer medication to patients in accordance with the provided guidelines. Also this result come in accordance with (Bucknall et al., 2019) who revealed that the majority of the considered nurse checking patient identification prior to giving drugs.

The present study showed that greater than half of critical care nurses didn't records monitoring data related to administered medication. On the other hand, all nurses reported the abnormal findings to physician. These findings may be related to the work overload or the lack of policy that guide medication administration.

This finding additionally is in concurred with (Westbrook et al., 2011) whom found that the studied nurses neglect to follow medication rules and record drug. This result come inconsistent with (Kirubakaran \& Amirtham, 2017) who studied "Knowledge and practice of intensive care unit nurses on intravenous drug administration" and reported the majority of the contemplated nurses were whined to nursing practice of the medication administration protocol.

\section{Conclusion}

The majority of the study participant had un satisfactory level of knowledge and practice.So these results showed that there is a wide gap between nurse's knowledge and their practice regarding medication administration errors.

\section{Recommendations}

Based on the findings of the present study and the researcher was suggested that;

- Implementation and dissemination of comprehensive, systematic, and continuous educational programs in order to enhance the knowledge and practices of nurse's on medication administration practices which will decrease the medication administration errors and using interactive teaching methods and technology in order to increase the efficiency of inservice trainings.

- Drug-related information are required in order to prevent the errors that may arise during practice to ensure quality. Designing safe work environment conducive for patient care delivery and reduce the occurrence of medication administration errors.

- The implications of this research study have relevance to future nursing research as well as other related disciplines in the following ways.

(5) Di Muzio, M., De Vito, C., Tartaglini, D., \& Villari, P. (2017) Knowledge, behaviours, training and attitudes of nurses during preparation and administration of intravenous medications in intensive care units (ICU). A multicenter Italian study. Applied Nursing Research, 38, 129-133

(6) Dyab, E. A., Elkalmi, R. M., Bux, S. H., \& Jamshed, S. Q. (2018). Exploration of nurses' knowledge, attitudes, andperceived barriers towards medication error reporting in a tertiary health care facility: A qualitative approach. Pharmacy, 6(4), 120 .

(7) Farag, A., Eweda, S., \& Elsayed, N. (2017). High Alert Medications. Alexandria Scientific Nursing Journal, 19(2), 1-24 .

(8) Gilani, S. A. (2020). Practices of Nurses in Administration of Safe Medication. I, 18(3), 32 .

(9) Hassan, R. M., \& Ahmed, S. T. (2012). Patient Safety: Assessing Nurses' Compliance. Journal of American Science, 8(1), 748-755 .

(10) Karttunen, M., Sneck, S., Jokelainen, J., \& Elo, S. (2020). Nurses' self-assessments of adherence to guidelines on safe medication preparation and administration in long-term elderly care. Scandinavian Journal of Caring Sciences, 34(1), 108-117 . 
(11) Kaur, A., \& Charan, G. S. (2018). A Study to Assess the Knowledge Regarding Medication Error among Staff Nurses at SGRD Hospital, Amritsar, Punjab. International Journal of Health Sciences and Research, 8(8. r) A-rir ،

(12) Kirubakaran, A. J., \& Amirtham, A. R. (2017). Knowledge and practice of intensive care unit nurses on intravenous drug administration. Indian Journal of Continuing Nursing Education, $18(1), 69$.

(13) Lan, Y.-H., Wang, K.-W. K., Yu, S., Chen, I.-J ‘.Wu, H.-F., \& Tang, F.-I. (2014). Medication errors in pediatric nursing: Assessment of nurses' knowledge and analysis of the consequences of errors. Nurse education today, 34(5), 821-828 .

(14) Mahesh, M., Hajira Saba, I., \& Gopi, A. (2016). Nursing perceptions of medication administration practices, reasons for errors and reporting of errors in a tertiary care hospital, Bangalore. International Journal of Community Medicine and Public Health, 3(2), 459 .

(15) Mansour, N. M. A. F. (2019). Effect of Maternity Nurses Knowledge and Practices Regarding the Medication Errors on Laboring Women Safety in Labor Unit Thesis. Helwan University.

(16) Márquez-Hernández, V. V., Fuentes-Colmenero, A. L., CañadasNúñez, F., Di Muzio, M., Giannetta, N., \& Gutiérrez-Puertas, L. (201 .)( ${ }^{9}$ Factors related to medication errors in the preparation and administration of intravenous medication in the hospital environment. PloS one, 14(7), e0220001 .

(17) Mohanty, S. (2016). Awareness of medication error, medication management and prevention amongstaff nurses in IMS \&Sum Hospital, Odisha. Nitte University Journal of Health Science, 6(4), 18 .
(18) Sa'ed, H. Z., Khaled, S. M., Kawasmi, B. M., Habeba, A. M., Hamadneh, A. T., Anabosi, H. H., . . . Al-Jabi, S. W. (2019). Knowledge about the administration and regulation of high alert medications among nurses in Palestine: a cross-sectionalstudy. BMC nursing, 18(1), 11 .

(19) Samundeeswari, A., \& Muthamilselvi, G. (2018). Nurses knowledge on prevention of medication errors. JMSCR, $6(3$.)

(20) Shahin, M., Mohamed, W., \& Sayed, M. (2012). Nurses Knowledge and Practices Regarding Enteral Nutrition at the Critical Care Department of Al-Manial University Hospital in Egypt: Impact of a Designed Instructional Program. Journal of American Science, 8(11), 397-404

(21) Shaikh, J., \& Al-Ruzaiqi, H. (2019). Knowledge and Perception of Preventable Medical Errors inSultanate of Oman. Madridge J Nurs, 4(1), 134-138.

(22) Teal, T. D. (2019). Associate and Baccalaureate Degree Nursing Students' Knowledge of and Attitudes toward Medication Errors and Reporting Medication Errors: Implications for Curriculum Development .

(23) World Health Organization.(2014), Reporting And Learning Systems For Medication Errors: The Role Of Pharmacovigilance Centres.

(24) Westbrook, J. I., Rob, M. I., Woods, A., \& Parry, D. (2011). Errors in the administration of intravenous medications in hospital and the role of correct procedures and nurse experience. BMJ quality \& safety, 20(12), 1027-1034.

(25) Zarea, K., Mohammadi, A., Beiranvand, S., Hassani, F., \& Baraz, S. (2018 .(Iranian nurses' medication errors: A survey of the types, the causes, and the related factors. International journal of Africa nursing sciences, 8, 112-116. 